This item was submitted to Loughborough's Institutional Repository (https://dspace.lboro.ac.uk/) by the author and is made available under the following Creative Commons Licence conditions.

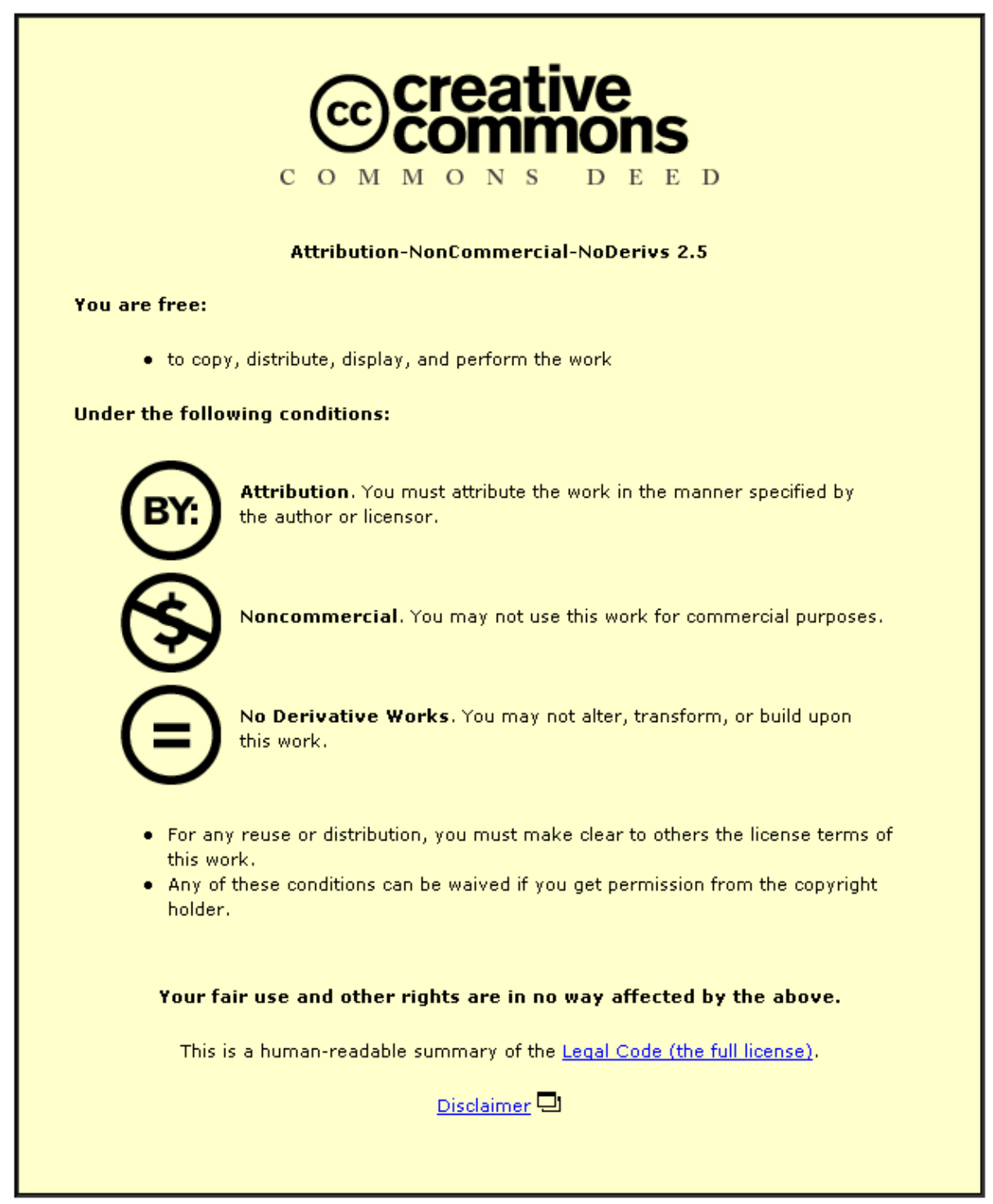

For the full text of this licence, please go to: http://creativecommons.org/licenses/by-nc-nd/2.5/ 


\title{
GENERATION OF SURFACE ACOUSTIC WAVES BY MOVING TRAINS
}

\author{
V.V. Krylov and C.C. Ferguson, \\ Centre for Research into the Built Environment, The Nottingham Trent University, \\ Burton Street, Nottingham NGl 4BU
}

\begin{abstract}
In this paper the theory of generation of ground surface acoustic waves by trains is developed using the Green's function formalism. Mechanical properties of the rail track and parameters of train and soil (including contact nonlinearity of track-soil system) are taken into account. It is shown that generated ground vibration spectra depend strongly on the geometrical parameters of track and train, on the mechanical properties of soil, and on the axle loads of the carriages. Simple practical methods are suggested to modify the spectra of railway-generated surface elastic woves and to reduce their level at choosen frequency bands.
\end{abstract}

\section{INTRODUCTION}

Railway-induced ground vibrations may cause noticeable movements of nearby buildings that result in damage or disamenity, both directly and by generating structureborne noise 1 .

For above-ground tracks, surface acoustic waves (mainly Rayleigh) carry most of the vibration energy. Spectra of railway-induced ground vibrations, including train-speed dependent components, have been studied experimentally 2,3 , and qualitative analysis has been attempted 4. However, no rigorous theoretical investigations of railway-generated ground vibrations have been carried out so far. In this paper we consider generation of ground surface acoustic waves caused by quasi-static pressure of wheel axles onto the track-soil system. In the case of welded rails and perfect wheels, this mechanism is the major contributor to trainspeeddependent components of the low-frequency vibration spectra (up to $50 \mathrm{~Hz}$ ), including the so called passage frequency $f_{p}=v / d$, where $v$ is train speed and $d$ is distance between sleepers.

An important aspect of the above is calculation of the track deflection curve, since it determines the frequency spectrum of Rayleigh surface waves generated by each sleeper. In turn, these spectra strongly affect the total vibration spectrum generated by a passing train.

\section{DETERMINATION OF THE TRACK DEFLECTION}

Since the track deflection distance is greater than the distance between sleepers, one can ignore the influence of rail periodic support by sleepers in the quasi-static problem of track deflection under the impact of a relatively slowly moving load. Instead we treat a track (i.e. two parallel rails with periodically fastened sleepers) as an Euler -Bernoulli elastic beam of uniform weight $p$ lying on an elastic or viscoelastic foundation occupying the semispace $z>0$.

If $\mathrm{E}$ and $\mathrm{I}$ are Young's modulus and the cross-sectional momentum of the beam, $\alpha$ is the proportionality coefficient of the elastic foundation, $x$ is the distance along the beam and $F_{m}$ is a vertical point force applied at $x=0$, then the traditional solution for $w$ has the form 5,6

$$
w=\left(F_{m} / 8 \operatorname{EI} \beta^{3}\right) \exp (-\beta|x|)[\cos (\beta x)+\sin (\beta|x|)]+p / \alpha,
$$

where $\beta=(\alpha / 4 \mathrm{EI})^{1 / 4}$. The constant $\alpha$ in eqn (1) depends particularly on the stiffness of the ground and of the rubber pads inserted between rail and sleepers. Calculation of $\alpha$ for typical British Rail tracks ${ }^{7}$ gives the values $\alpha=61.8 \mathrm{MN} / \mathrm{m}^{2}$ and $\beta=1.28 \mathrm{~m}^{-1}$.

A more recent approach to an analogous problem in mechanics ${ }^{6}$ acknowledges that track-soil contacts can respond only to compressive stresses. Thus the contact nonlinearity of a real boundary between track and ground is taken into account.

Analysis of this model shows ${ }^{6}$ that for values of the axle load $F_{m} \leq F_{c r}=(2 p / \beta) \exp (\pi)$ the simple classical solution (1) which describes a continuous contact between track and foundation remains valid. However, for $F_{m}>$ $F_{\mathrm{cr}}$ the solution becomes more complicated and involves peripheral bulges of the track with loss of contact between track and soil. In this case the problem is solved numerically for coordinates $x_{0}$ and $x_{1}$ of the deformed track where it intersects ground level $(z=0)$, and for the 
five coefficients describing the shape of the deflection curve as a function of applied load.

For our purposes it is sufficient to use a rather rough analytical approximation of the deflection function for $F_{m}$ $>F_{c r}$, where only one parameter $x_{0}$ as a function of $F_{m}$ is taken into account:

$$
w= \begin{cases}p / \alpha+\left(F_{m^{\prime}} / 8 \mathrm{EI} \beta^{3}\right) \cos \left(\pi x / 2 x_{0}\right), & |x|<x_{0}, \\ 0, & |x|>x_{0} .\end{cases}
$$

Numerical data for $\mathrm{x}_{0}$ as a function of $\mathrm{F}_{\mathrm{m}}$ calculated in the paper ${ }^{6}$ over the range $1.6 / \beta<x_{0}<\pi / \beta$ can be approximated by the equation

$$
x_{0}=(1 / \beta)\left\{\pi-\left[0.4 \log \left(\beta F_{m} / 2 e^{\pi} p\right)\right]^{0.3}\right\} .
$$

\section{RADIATION OF AN INDIVIDUAL SLEEPER}

To calculate low-frequency elastic waves generated by individual sleepers let us consider each sleeper as a point source of vertical force applied to the surface $z=0$ at $x=0$ and $y=0$, with time dependence determined by the passage of the deflection curve through the sleeper:

$$
P(t)=F_{m}\left[2 w(v t) / w_{\max }\right]\left(d / x_{0}\right),
$$

where $w_{\max }$ is the maximum value of $w(v t)$. Terms on the right of $F_{m}$ take into account the distribution of axle load between sleepers within the deflection curve. We shall now make use of results from the well-known axisymmetric Lamb problem for the excitation of an elastic semispace by a vertical point force applied to the surface. The solution of this problem describes the corresponding components of the dynamic Green's tensor $G_{z i}$ (or, for simplicity, the components of the Green's function) for the elastic semispace. This function satisfies the dynamic equations of elasticity for a semispace, assumed isotropic and homogeneous, and the appropriate boundary conditions 8,9 .

In what follows only Rayleigh surface waves (the Rayleigh part of the Green's function) are considered. For these waves the spectral density of the vertical vibrational velocity at $z=0$ may be written in the form 8

$$
v_{z}(\rho, \omega)=P(\omega) G_{z z}(\rho, \omega)=V(\omega)\left(1 / V_{\rho}\right) \exp (i k \rho-i 3 \pi / 4)
$$

where

$$
V(\omega)=(\pi / 2)^{1 / 2} \mathrm{P}(\omega)(-\mathrm{i} \omega) \mathrm{q}\left(\mathbf{k}_{\mathrm{R}}\right)^{1 / 2} \mathbf{k}_{\mathrm{t}}{ }^{2 / \mu \mathrm{F}^{\prime}\left(\mathrm{k}_{\mathrm{R}}\right)}
$$

Here $\rho=\left[\left(x-x^{\prime}\right)^{2}+\left(y-y^{\prime}\right)^{2}\right]^{1 / 2}$ is the distance between the source (with current coordinates $x^{\prime}, y^{\prime}$ ) and the point of observation (with coordinates $x, y$ ), $\omega=2 \pi f$ is a circular frequency, $k_{R}=\omega / c_{R}$ is the wavenumber of a Rayleigh surface wave where $c_{R}$ is the Rayleigh wave propagation velocity, $k_{1}=\omega / c_{1}$ and $k_{t}=\omega / c_{t}$ are the wavenumbers of longitudinal and shear bulk elastic waves, where $c_{1}=\left[(\lambda+2 \mu) / \rho_{0}\right]^{1 / 2}$ and $c_{t}=\left(\mu / \rho_{0}\right)^{1 / 2}$ are longitudinal and shear propagation velocities, $\lambda$ and $\mu$ are Lame constants, $\rho_{0}$ is the ground mass density, and $q=\left(k_{R}{ }^{2}-k_{1}^{2}\right)^{1 / 2}$. The factor $F^{\prime}\left(k_{R}\right)$ is a derivative of the Rayleigh determinant $F(k)=\left(2 k^{2}-k_{t}^{2}\right)^{2}-4 k^{2}\left(k^{2}-\right.$ $\left.\mathrm{k}_{\mathrm{t}}\right)^{\mathrm{l} / 2}\left(\mathrm{k}^{2}-\mathrm{k}_{\mathrm{l}}\right)^{1 / 2}$ taken at $\mathrm{k}=\mathrm{k}_{\mathrm{R}}$, and

$$
P(\omega)=(1 / 2 \pi) \int_{-\infty}^{\infty} P(t) \exp (i \omega t) d t
$$

is a Fourier transform of $\mathrm{P}(\mathrm{t})$.

In the case under consideration, $P(\omega)$ should be determined separately for $F_{m} \leq F_{c r}$ and for $F_{m}>F_{c r}$. Substituting (1) and (2) into (7), one can easily obtain the analytical expressions for $P(\omega)$ :

$$
\begin{aligned}
P(\omega)= & \left(F_{m} d / \pi x_{0}\right)\left\{(2 \beta v+\omega) /\left[(\beta v)^{2}+(\beta v+\omega)^{2}\right]+\right. \\
& \left.(2 \beta v-\omega) /\left[(\beta v)^{2}+(\beta v-\omega)^{2}\right]\right\}, \\
& \text { for } F_{m} \leq F_{c r} ; \\
P(\omega)= & \left(F_{m} d / \pi x_{0}\right)\left(2 \pi v / x_{0}\right) \cos \left(\omega x_{0} / v\right) /\left[\omega^{2}\right. \\
& \left.\left(\pi v / 2 x_{0}\right)^{2}\right], \quad \text { for } F_{m}>F_{c r}
\end{aligned}
$$

where $x_{0}$ is determined by eqn (3).

One can generalise these results to describe the action of two axle loads separated by the distance a (the case of a bogie):

$$
P_{b}(\omega)=2 P(\omega) \cos (\omega a / 2 v)
$$

\section{CONSIDERATION OF ALL SLEEPERS AND AXLES}

To calculate the vibration field radiated by a complete moving train requires the superposition of fields generated by each sleeper activated by all axles of all carriages, with the time and space differences between sources (sleepers) being taken into account.

Using the Green's function formalism this may be written in the form

$$
v_{z}(x, y, \omega)=\int_{-\infty-\infty}^{\infty} \int^{\infty} P\left(x^{\prime}, y^{\prime}, \omega\right) G_{z z}(\rho, \omega) d x^{\prime} d y^{\prime},
$$

where $P\left(x^{\prime}, y^{\prime}, \omega\right)$ describes the total distribution of forces along the track. This distribution is found by taking a Fourier transform of the time and space dependent track load function $P\left(t, x^{\prime}, y^{\prime}\right)$. 
For the case of a train with equal carriages this load function may be written in the form

$$
\begin{gathered}
\mathrm{P}\left(\mathrm{t}, \mathrm{x}^{\prime}, \mathrm{y}^{\prime}=0\right)=\sum_{m=-\infty}^{\infty} \sum_{n=0}^{N-1}\left[\mathrm{P}\left(\mathrm{t}-\left(\mathrm{x}^{\prime}+\mathrm{nL}\right) / \mathrm{v}\right)+\right. \\
\left.\mathrm{P}\left(\mathrm{t}-\left(\mathrm{x}^{\prime}+\mathrm{M}+\mathrm{nL}\right) / \mathrm{v}\right)\right] \delta\left(\mathrm{x}^{\prime}-\mathrm{md}\right) \delta\left(\mathrm{y}^{\prime}\right) .
\end{gathered}
$$

where $\mathrm{N}$ is the number of carriages, $\mathrm{M}$ is the distance between bogies in each carriage, $\mathrm{L}$ is the total carriage length, $\delta(z)$ is the Dirac's delta-function.

Substituting eqn (12) into eqn (7) and then into eqn (11), and making simple transformations, one obtains the following expression for the frequency spectra of vertical vibrations at $\mathrm{z}=0$ generated by a moving train:

$$
\begin{gathered}
\mathrm{v}_{\mathrm{Z}}\left(0, \mathrm{y}_{0}, \omega\right)=-\mathrm{iV}(\omega) \sum_{m=-\infty}^{\infty} \sum_{n=0}^{N-1}\left[\exp \left(-\gamma \omega \rho_{\mathrm{m}} / c_{\mathrm{R}}\right) / \sqrt{ } \rho_{\mathrm{m}}\right] \\
{[1+\exp (\mathrm{iM} \omega / \mathrm{v})] \exp \left(\mathrm{i}(\omega / \mathrm{v})(\mathrm{md}+\mathrm{nL})+\mathrm{i}\left(\omega / \mathrm{c}_{\mathrm{R}}\right) \rho_{\mathrm{m}}\right)}
\end{gathered}
$$

In writing eqn (13) we account for attenuation in soil by replacing $1 / c_{R}$ in the exponentials by the complex value $1 / c_{R}+i \gamma / c_{R}$, where $\gamma<<1$ is a constant describing the "strength" of dissipation of Rayleigh waves in soil (eqn (13) implies a linear frequency dependence of soil attenuation, in agreement with experimental data ${ }^{10}$ ).

The summation over $\mathrm{m}$ in eqn (13) considers an infinite number of sleepers. However, the contribution of remote sleepers is small because of soil attenuation and cylindrical spreading, and a few hundred sleepers are adequate for practical calculations.

It follows from eqn (13) that the spectrum of traininduced vibrations is quasi-discrete, with the maxima at frequencies determined by the condition $(\omega / \mathrm{v})(\mathrm{md}+\mathrm{nL})=$ $2 \pi \mathrm{l}$, where $1=1,2,3, \ldots$ Obviously, $n=0$ corresponds to the passage frequencies $f_{p} s$ determined by the sleeper period d. Other more frequent maxima are determined either by the carriage length $L(m=0)$ or by a combination of both parameters (for $n \neq 0, m \neq 0$ ).

There are also many zeros present in the train vibration spectra. These zeros may be used in practice for suppressing vibrations at chosen frequencies. The most important zeros are those which do not depend on a number of sleepers or carriages and are determined only by the geometrical parameters of a carriage. One of these zeros is determined by the distance a between the wheel axles in a bogie (see eqn (10) for the spectrum $P_{b}$ ). Setting $P_{b}$ to zero, one can obtain $f_{z}=(v / a)(n+1 / 2)$ for zero-frequencies. If, for instance, we want to use this condition to suppress one of the train passage frequencies $f_{p} s$, we should choose $f_{z}$ to be equal to $f_{p} s$. It follows from this that the value of a should be determined by

$$
a=(d / s)(n+1 / 2)
$$

It is sensible to choose a value of a close to existing values. For British Rail heavy-freight carriages $\mathrm{a}=2.2 \mathrm{~m}$ usually. Therefore, to suppress the main passage frequency $(s=1)$ one can chose $a=2.45 \mathrm{~m}$ corresponding to $\mathrm{n}=3$ in eqn (14).

Other important zero frequencies reflect the distance $M$ between bogies in a carriage. Condition (14) is also valid for this case if $a$ in eqn (14) is replaced by $M$. The value of $M$ providing suppression of the main passage frequency which is closest to the British Rail standard $(M=4.88 \mathrm{~m})$ is $4.55 \mathrm{~m}$, corresponding to $\mathrm{n}=6$.

\section{NUMERICAL CALCULATIONS AND DISCUSSION}

Numerical calculations of train-induced ground vibrations described by equations (13), (6)-(10) and (3) have been carried out for different values of applied load $F_{m}$, train speed $\mathbf{v}$, soil attenuation coefficient $\gamma$, and for different geometrical parameters of both track and train: d, a, L, M. The elastic parameters of the soil considered were $c_{R}=$ $250 \mathrm{~m} / \mathrm{s}, c_{\mathrm{t}}=272 \mathrm{~m} / \mathrm{s}, \mathrm{c}_{\mathrm{l}}=471 \mathrm{~m} / \mathrm{s}$ (corresponding to a Poisson's ratio of $\sigma=0.25$ ). The mass density of soil $\rho_{0}$ was set at $2000 \mathrm{~kg} / \mathrm{m}^{3}$.

Figure 1 shows the theoretical frequency spectra for a 5-carriage train moving with speed $\mathrm{v}=50 \mathrm{~km} / \mathrm{h}$. Calculations have been carried out for an axle load of 100 $\mathrm{kN}$ (below the critical value $\mathrm{F}_{\mathrm{cr}}=108.3 \mathrm{kN}$ determined for a typical track weight with concrete sleepers, $p=3$ $\mathrm{kN} / \mathrm{m}$ ) and for a load of $200 \mathrm{kN}$ (above the critical value). Geometrical parameters of the train were chosen typical of British Rail heavy-freight trains ${ }^{2}: L=8.3 \mathrm{~m}, M=4.88 \mathrm{~m}$ and $\mathrm{a}=2.2 \mathrm{~m}$. The soil attenuation parameter $\gamma$ was chosen to be 0.00478 . According to the figure, generation is more efficient at $200 \mathrm{kN}$ axle load, especially for higher frequencies. Note that the shapes and intensities (in $\mathrm{dB}$ ) of the calculated spectra are in good agreement with experimental data 2,3 .

The vibration spectra calculated for different train speeds, $v=50 \mathrm{~km} / \mathrm{h}$ and $v=40 \mathrm{~km} / \mathrm{h}$, are shown in Fig.2 for an axle load of $100 \mathrm{kN}$. The parameters of track, train and soil are the same as before. As expected, changing the train speed displaces the spectral maxima.

Fig. 3 shows how choice of the distance a between axles in a bogie can suppress ground vibration intensity at the main passage frequency $f_{p}=v / d$. The corresponding distance $\mathrm{a}=2.45 \mathrm{~m}$ was calculated using eqn (14) for $\mathrm{d}=$ $0.7 \mathrm{~m}$. The axle load was $100 \mathrm{kN}$, the train speed $v=50$ $\mathrm{km} / \mathrm{h}$, and the distance $\mathrm{y}_{0}=30 \mathrm{~m}$, other parameters being same as in previous figures. According to the figure, the vibration level at the lowest passage frequency is suppressed by about $20 \mathrm{~dB}$, i.e. a factor of 10 relative to 
that for $a=2.2 \mathrm{~m}$. Of course, the same effect could be achieved by changing the sleeper period $d$.

\section{CONCLUSIONS}

Generation of surface acoustic waves by moving trains has been considered theoretically. Analytical expressions for the ground vibration spectra have been obtained as functions of track, train and soil parameters.

Numerical calculations have shown that ground vibration spectra depend strongly on the axle loads of the carriages: if the axle load exceeds a critical value beyond which peripheral bulges appear in the track, the vibration level increases significantly, especially at higher frequencies. The shapes and intensities of the spectra are in good agreement with experimental data.

By proper selection of the distance between wheel axles in a bogie, and between bogies in a carriage (or between sleepers in a track) it is possible effectively to suppress vibration levels at the train passage frequencies.

\section{REFERENCES}

1. Walker, J.G. \& Ridler, S.A., Prediction and assessment of ground-bome noise from underground railways. Proc. Inst. of Acoustics, 13 (1991) 1-5.

2. Dawn, T.M., Ground vibrations from heavy freight trains. Joumal of Sound and Vibration, 87 (1983) 351-356.

3. Melke, J., Noise and vibration from underground railway lines. Joumal of Sound and Vibration, 120 (1988) 391-406.

4. Ford, R.A.J., Inhibiting the transmission of ground-borne vibrations by placing masses on the surface of the ground. The Institution of Engineers Australia Vibration and Noise Conference, Melboume, 1990, p. 227-231.

5. Timoshenko, S., Strength of Materials, Part 2, Van Nostrand, New York., 1942.

6. Weitsman, Y., On foundations that react in compression only. Transactions of the ASME: Joumal of Applied Mechanics 92 (1970) 1019-1030.

7. Brockley, C.A., The influence of track support structure and locomotive traction characteristics on short wavelength corrugations. Wear, 153 (1992) 315-322.

8. Krylov, V.V., On the theory of surface acoustic wave generation by electric spark discharge. Journal of Physics $D$ : Applied Physics 25 (1992) 155-161.

9. Krasil'nikov, V.A., \& Krylov, V.V., Introduction to Physical Acoustics, Nauka, Moscow, 1984 (in Russian).

10. Gutovski, T.G. \& Dym, C.L., Propagation of ground vibration: a review. Joumal of Sound and Vibration, 49 (1976) 179-193.

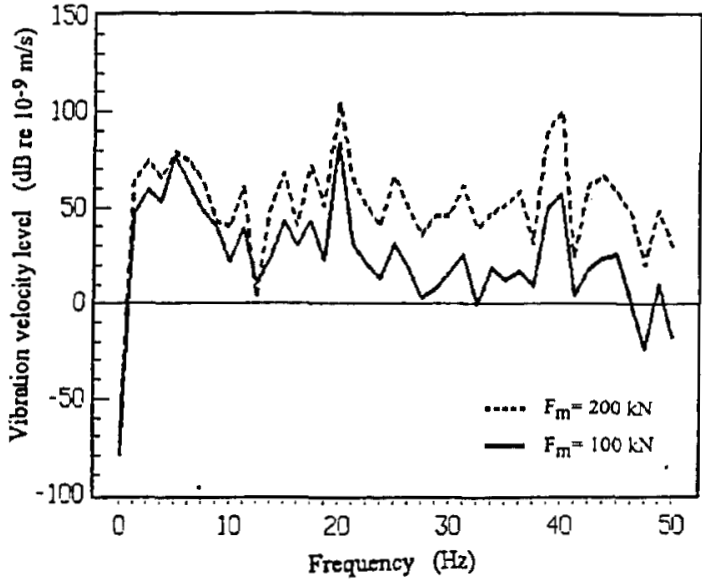

Fig.1. Ground vibration spectra for different axle loads, $F_{m}$

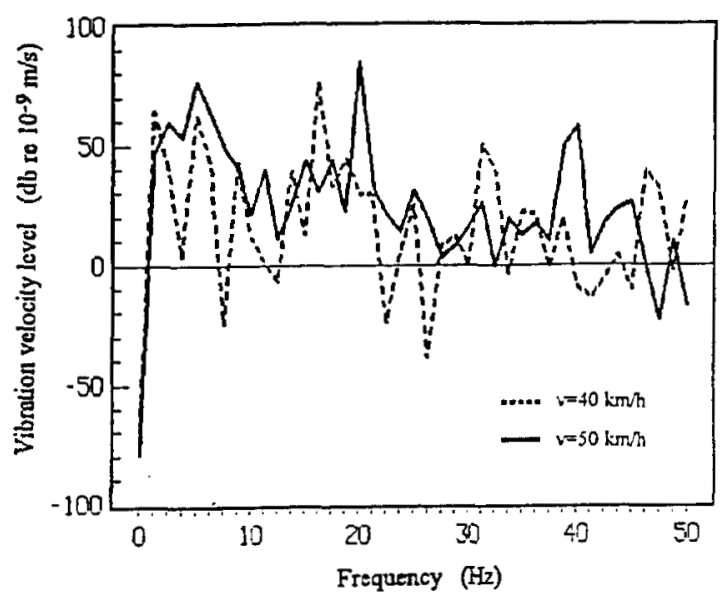

Fig.2. Influence of a train speed $v$ on ground vibration spectra

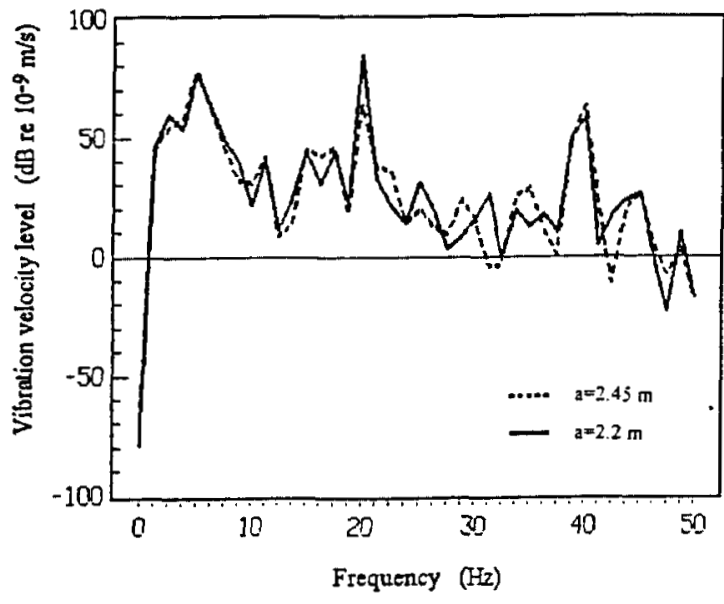

Fig.3. Suppression of ground vibrations by selecting the appropriate distance $a$ 